This document is confidential and is proprietary to the American Chemical Society and its authors. Do not copy or disclose without written permission. If you have received this item in error, notify the sender and delete all copies.

\title{
Terpene and dextran renewable resources for the synthesis of amphiphilic biopolymers
}

\begin{tabular}{|r|l|}
\hline Journal: & Biomacromolecules \\
\hline Manuscript ID: & bm-2013-01521f.R2 \\
\hline Manuscript Type: & Article \\
\hline Date Submitted by the Author: & n/a \\
\hline Complete List of Authors: & $\begin{array}{l}\text { Alvès, Marie-Hélène; IPREM-Equipe de Physique et Chimie des Polymères,, } \\
\text { CNRS - Université de Pau et des Pays de I'Adour } \\
\text { Sfeir, Huda; IPREM-Equipe de Physique et Chimie des Polymères,, } \\
\text { Tranchant, Jean-François; LVMH Recherche Parfums et Cosmétiques, } \\
\text { Gombart, Emilie; LVMH Recherche Parfums et Cosmétiques, } \\
\text { Sagorin, Gilles; DRT, Dérivés Résiniques et Terpéniques, } \\
\text { Caillol, Sylvain; Institut Charles Gerhardt UMR CNRS 5253 Equipe } \\
\text { Ingénierie et Architecture Macromoléculaire, ENSCM, } \\
\text { Billon, Laurent; IPREM EPCP UMR 5254, Chemistry } \\
\text { Save, Maud; IPREM-Equipe de Physique et Chimie des Polymères, CNRS - } \\
\text { Université de Pau et des Pays de l'Adour }\end{array}$ \\
\hline
\end{tabular}




\title{
Terpene and dextran renewable resources for the synthesis of amphiphilic biopolymers
}

\author{
Marie-Hélène Alvès, $\dagger$ Huda Sfeir, $\uparrow$ Jean-François Tranchant, $\$$ Emilie \\ Gombart, $₫$ Gilles Sagorin, ' Sylvain Caillol, $\equiv$ Laurent Billon, $\dagger$ Maud
}

Save $\dagger^{*}$

$\dagger$ CNRS, University of Pau \& Pays Adour, UMR 5254, IPREM, Equipe de Physique et Chimie des Polymères, 2 avenue du Président Angot, Pau, F-64053, France

\$ LVMH Recherche Parfums et Cosmétiques, 185 Av. de Verdun, St Jean de Braye, F45804, France

- DRT, Dérivés Résiniques et Terpéniques, 30 rue Gambetta, Dax, F-40100, France

$\equiv$ Institut Charles Gerhardt UMR CNRS 5253 Equipe Ingénierie et Architecture Macromoléculaire, ENSCM, 8 rue de l'Ecole Normale, 34296 Montpellier, France 


\section{ABSTRACT}

The present work shows the synthesis of amphiphilic polymers based on the hydrophilic dextran and the hydrophobic terpenes as renewable resources. The first step concerns the synthesis of functional terpene molecules by thiol-ene addition chemistry involving amino- or carboxylic acid thiols and dihydromyrcenol terpene. The terpene modified polysaccharides were subsequently synthesized by coupling the functional terpenes with dextran. A reductive amination step produced terpene end-modified dextran with $94 \%$ of functionalization while the esterification step produced three terpene grafted dextrans with a number of terpene units per dextran of 1, 5 and 10. The amphiphilic renewable grafted polymers were tested as emulsifiers for the stabilization of liquid miniemulsion of terpene droplets dispersed in an aqueous phase. The average hydrodynamic diameter of the stable droplets was observed at $c a$. $330 \mathrm{~nm}$.

KEYWORDS : renewable resources, polysaccharide, terpene, thiol-ene chemistry

\section{INTRODUCTION}

The fossil resources depletion is leading to a growing interest toward materials derived from sustainable resources. Polysaccharides and terpenes are two interesting classes of materials issued from renewable biomass. ${ }^{1-6}$ Polysaccharides are mainly hydrophilic and terpenes belong to hydrocarbon-rich biomass. Terpenes are either branched or cyclic unsaturated molecules which are extracted from the resin produced by conifer trees. Terpenes are an interesting class of molecules as they can represent an alternative to fossil molecules but also to hydrocarbon-rich biomass feedstock such as oilseeds and palm oil. Different terpene molecules are distilled from either turpentine or from paper oil, a by-product of the paper-making industry. Among the first recovered products, $\alpha$ and $\beta$-pinene are an important 
class of molecules which are industrially transformed into a series of valuable terpenes by various chemical reactions. Some terpene building blocks have been used for the synthesis of different hydrophobic polymers as recently reviewed in the literature. ${ }^{5-7}$ Among the examples of terpene-based polymers, ${ }^{5-6,8-12}$ the synthesis of amphiphilic polymers were limited to the design of terpene end-modified poly(ethylene oxide) polymers by anionic ring-opening polymerization of ethylene oxide from terpene-based initiator. ${ }^{13,14}$

In parallel, the increasing demand of materials with high performances requires modification of natural polymers. ${ }^{15}$ Numerous examples of polysaccharide modification through synthetic polymer grafting via for instance controlled radical polymerization ${ }^{16}$ or ring opening polymerization ${ }^{17-20}$ techniques have been described in the literature. Hydrophobically modified polysaccharides with emulsifying properties have also been synthesized through the grafting of hydrophobic molecules coming from fossil resources. ${ }^{21-25}$ In this context, the renewable feedstock of abundantly available terpenes and polysaccharides is attractive for the synthesis of new amphiphilic biopolymers.

To the best of our knowledge, the synthesis of amphiphilic dextrans hydrophobically modified by terpenes has never been reported. In the present work, the synthesis of functional terpenes by thiol-ene reactions will offer the possibility to synthesize both linear and grafted amphiphilic biopolymers (schemes 1 and 2). It is noteworthy that there are a few examples in the literature on the use of thiol-ene coupling involving terpenes. ${ }^{12,26}$ Recently, Meier and coworkers made use of thiol-ene chemistry to produce limonene-based polyesters by polycondensation of difunctional modified terpenes. ${ }^{12}$

Herein, we focused our attention on a linear low molar mass dextran as model polysaccharide, dextran being a glucose-based neutral bacterial polysaccharide. Among the fragrant terpenic molecules, dihydromyrcenol (2,6-Dimethyloct-7-ene-2-ol, DHM) was chosen as a non toxic terpene containing a mono-substituted vinylic function suitable for 
applying the chosen thiol-ene addition chemistry (Scheme 1). ${ }^{27}$ Dextran will be modified by either reductive amination of the chain end with amino-derivatized DHM (Scheme 1, route A) or by esterification of hydroxyl backbone with carboxylic acid derivatized DHM (Scheme 1, route B). The efficiency of the terpene grafted dextran as polymeric emulsifier will be assessed through its ability to stabilize liquid droplets of dihydromyrcenol fragrance in water. The dispersion of such molecules by a renewable biopolymer is of interest for cosmetic field.

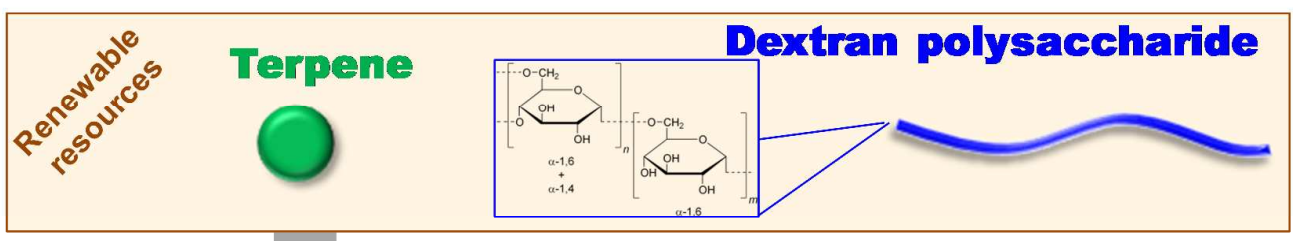

Thiol-ene click chemistry

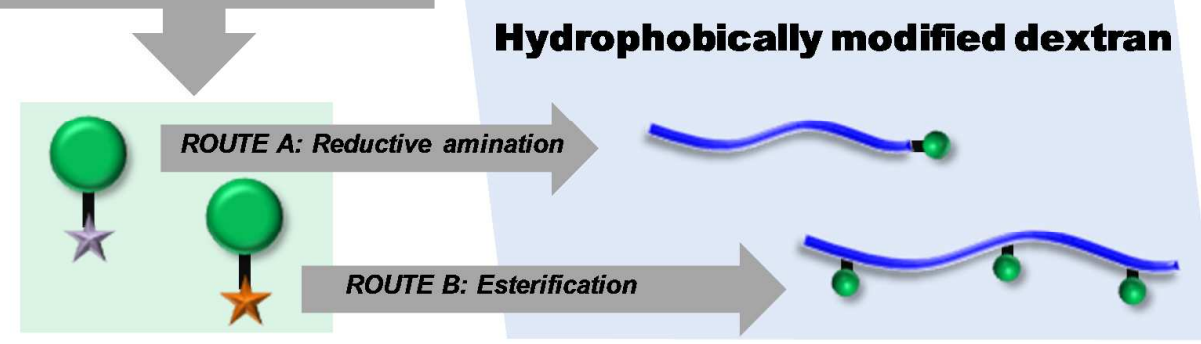

Scheme 1. Synthetic approach followed to obtain amphiphilic biopolymers

\section{EXPERIMENTAL PART}

Materials. 3-mercaptopropionic acid (Aldrich, 99 \%), 2,2'-Azobis(2-methylpropionitrile) (AIBN, Aldrich 98\%), 2,6-Dimethyloct-7-ene-2-ol also named dihydromyrcenol (DHM, 99.5 \%), was supplied by Dérivés Résiniques Terpéniques (DRT company), cysteamine hydrochloride (Fluka, $98 \%$ ), triethylamine (Aldrich, $99 \%$ ), sodium cyanoborohydride (Aldrich, $95 \%$ ), N,N'-Dicyclohexylcarbodiimide (DCC, Aldrich, $99 \%$ ), hexadecane (SigmaAldrich, 99 \%). Dimethylsulfoxide (DMSO, Technical grade, VWR) was dried over 
molecular sieves which were previously dried under vaccum at $100{ }^{\circ} \mathrm{C}$. Fractionated dextrans were purchased from Serva Electrophoresis (dextran 4 and dextran 8).

Synthesis of functional terpenes by thiol-ene addition chemistry (Scheme 2). Terpene 1 displayed in Scheme 2 was synthesized as follows: $2 \mathrm{~g}$ of DHM $\left(1.3 \times 10^{-2} \mathrm{~mol}\right), 2.9 \mathrm{~g}$ of cysteamine hydrochloride $\left(2.6 \times 10^{-2} \mathrm{~mol}\right)$ and $105 \mathrm{mg}$ of AIBN $\left(6.4 \times 10^{-4} \mathrm{~mol}\right)$ were mixed in a round bottom flask sealed with a rubber septum prior degassing 15 minutes with nitrogen flow. We should note that cysteamine hydrochloride was not initially soluble in DHM terpene but the solubility increased during the reaction performed at $80^{\circ} \mathrm{C}$. After 24 hours of reaction, the recovered product was an ammonium salt and the final amine (Terpene 1) was recovered in dichloromethane by 2 liquid-liquid extractions using a saturated sodium bicarbonate aqueous solution. The organic phase was dried over magnesium sulfate, filtered and evaporated to recover the pure Terpene $\mathbf{1}$ as pale yellow oil (Figure 1).

${ }^{1} \mathrm{H}$ NMR (400 MHz, DMSO-d6, $\delta$ in ppm) 2.57 (t, 2H, NH2-CH2-CH2-S), 2.48 (t, 2H, NH2CH2-CH2-S), 2.45 (CH-CH2-CH2-S), 1.51 (m, 1H, (CH2)2-CH-CH3), 1.51 (m, 1H, CHCHH-CH2-S), 1.30 (m, 1H, CH-CHH-CH2-S), 1.30 (t, 2H, HO-(CH3)2C-CH2-CH2), 1.25 (m, 1H, CH-CH2-CH2-CH2), 1.07 (m, 2H, CH-CH2-CH2-CH2), 1.05 (s, 6H, (CH3)2$\mathrm{C}(\mathrm{OH})), 0.85(\mathrm{~d}, 3 \mathrm{H}, \mathrm{CH} 3-\mathrm{CH})$.

${ }^{13} \mathrm{C}$ NMR (100 MHz, DMSO-d6, $\delta$ in ppm) $69.15(\mathrm{Ck}), 44.35$ (Ce), $41.97(\mathrm{Ci}), 37.39(\mathrm{Cb})$, 37.08 (Cd'), 35.92 (Ch), 32.03 (Cc), 29.74 (Cf), 29.31 (Ca), $21.65(\mathrm{Cd}), 19.64(\mathrm{Cg})$.

Terpene 2 displayed in Scheme 2 was synthesized as follows: $20 \mathrm{~g}$ of DHM $\left(1.3 \times 10^{-1} \mathrm{~mol}\right)$, $13.6 \mathrm{~g}$ of 3 -mercaptopropionic acid $\left(1.3 \times 10^{-1} \mathrm{~mol}\right)$ and $210 \mathrm{mg}$ of $\operatorname{AIBN}\left(1.3 \times 10^{-3} \mathrm{~mol}\right)$ were mixed in a round bottom flask sealed with a rubber septum prior degassing for 15 minutes with nitrogen flow. The reaction was carried out at $80{ }^{\circ} \mathrm{C}$ for 4 hours and the final product (non colored oil, quantitative product, Figure 1) was used without purification. 
${ }^{1} \mathrm{H}$ NMR (400 MHz, DMSO-d6, $\delta$ in ppm) 4.07 (OH), 2.65 (t, 2H, HOOC-CH2-CH2-S), 2.45 (t, 2H, HOOC-CH2-CH2-S), 2.50 (m, 2H, CH-CH2-CH2-S), 1.49 (m, 1H, (CH2)2-CH-CH3), 1.49 (m, 1H, CH-CHH-CH2-S), 1.32 (m, CH-CHH-CH2-S), 1.32 (t, HO-(CH3)2C-CH2$\mathrm{CH} 2), 1.27$ (m, 2H, CH-CH2-CH2-CH2), 1.07 (m, 2H, CH-CH2-CH2-CH2), 1.05 (s, 6H, (CH3)2-C(OH)), $0.83(\mathrm{~d}, 3 \mathrm{H}, \mathrm{CH}-\mathrm{CH})$.

${ }^{13} \mathrm{C}$ NMR (100 MHz, DMSO-d6, $\delta$ in ppm) $69.08(\mathrm{Ck}), 43.96(\mathrm{Ce}), 36.82(\mathrm{Cb}), 36.26$ (Cd'), $34.50(\mathrm{Ci}), 31.49(\mathrm{Cc}), 29.25(\mathrm{Cf}), 28.85(\mathrm{Ca}), 26.34(\mathrm{Ch}), 21.14(\mathrm{Cd}), 19.12(\mathrm{Cg})$.

Synthesis of terpene chain end modified dextran. Dextran $4\left(200 \mathrm{mg}, M_{\mathrm{n}}=2600 \mathrm{~g} \cdot \mathrm{mol}^{-1}\right.$, $\left.7.7 \times 10^{-5} \mathrm{~mol}\right)$ were mixed with $0.6 \mathrm{ml}$ of distilled water. A solution of Terpene $1(333 \mathrm{mg}$, $1.4 \times 10^{-3} \mathrm{~mol}$ ) was prepared with $0.4 \mathrm{~mL}$ of DMSO and subsequently added into the aqueous solution of dextran 4. After 2 hours of stirring, $22 \mathrm{mg}$ of sodium cyanoborohydride $\left(3.6 \times 10^{-4}\right.$ mol) were added into the round bottom flask and the reaction proceeded overnight at room temperature. The initial cloudy solution became a clear, slightly yellow solution. The polymer was precipitated three times from an aqueous solution into methanol and finally dried under vaccum. The final Dext-DHM polymer is a white powder (yield $70 \%$ ).

Grafting of Terpene 2 for the synthesis of hydrophobically modified dextran. Dextran 8 $\left(1 \mathrm{~g}, M_{\mathrm{n}}=6600 \mathrm{~g} \cdot \mathrm{mol}^{-1}, 1.5 \times 10^{-4} \mathrm{~mol}\right)$ were mixed with $6 \mathrm{~mL}$ of dried DMSO and heated at $60{ }^{\circ} \mathrm{C}$ before adding $N, N^{\prime}$-Dicyclohexylcarbodiimide $\left(3.7 \mathrm{~g}, 1.8 \times 10^{-2} \mathrm{~mol}\right)$. A solution of Terpene $2\left(3.9 \mathrm{~g}, 1.5 \times 10^{-2} \mathrm{~mol}\right)$ was prepared with $2 \mathrm{~mL}$ of DMSO and subsequently poured into the round bottom flask containing the dextran 8 and DCC solution. The initial number of moles of DHM terpene over the number of moles of anhydroglucose units (AGU), $x=$ $\left(m_{\mathrm{DHM}, 0} / M_{\mathrm{DHM}}\right) /\left(m_{\mathrm{dextran}, 0} / M_{\mathrm{AGU}}\right)$, is equal to $0.24,1.22$ and 2.44 respectively for the synthesis of Dext-graft-DHM 1 , Dext-graft-DHM 5 and Dext-graft-DHM 10 grafted copolymers. After 18 hours at $60{ }^{\circ} \mathrm{C}$, the modified dextran was precipitated three times into methanol in order to 
eliminate free terpene. The final amphiphilic polymer was recovered as a white powder after drying process.

Preparation of DHM liquid miniemulsion. Dext-graft-DHM ${ }_{10}(50 \mathrm{mg})$ was mixed with 9 $\mathrm{mL}$ of a phosphate buffer solution $(\mathrm{pH}$ ) before adding a solution containing $1 \mathrm{~g}$ of dihydromyrcenol and $25 \mathrm{mg}$ of hexadecane. The liquid emulsion was then subjected to high shear pressure using a Vibra Cell 72408 ultrasonicator for 5 min at amplitude of 30\% (round bottom flask placed into an ice bath).

Instrumentation. Proton, carbon, and two-dimensional (COSY for COrrelation SpectroscopY, HSQC for heteronuclear single quantum coherence) nuclear magnetic resonance (NMR) spectra were recorded at $25^{\circ} \mathrm{C}$ on a Brüker $400 \mathrm{MHz}$ spectrometer. The average droplet diameters $\left(D_{\mathrm{h}}\right)$ were measured using a Vasco DL135 dynamic light scattering. The number average molar mass $\left(M_{\mathrm{n}}\right)$ and dispersity $\left(M_{\mathrm{w}} / M_{\mathrm{n}}\right)$ of dextran were measured by aqueous size exclusion using the following system: 2 columns Tosoh TSK PW 2500 et TSK PW 6000, Agilent 1260 Infinity pump, Waters 717 plus automatic injector, Multi-Angle Light Scattering MALS Wyatt EOS (laser $\lambda=690 \mathrm{~nm}$, cellule K5), Wyatt Optilab T-rEX refractometer $\left(\lambda=658 \mathrm{~nm}, 25^{\circ} \mathrm{C}\right)$, ASTRA 6 software. Acetic acid $0.2 \mathrm{M}$ and ammonium acetate buffer $0.15 \mathrm{M}$ was used as eluent at $0.5 \mathrm{~mL} \cdot \mathrm{min}^{-1}$ flow rate. Samples of dextran at concentration of 5 g.L $\mathrm{L}^{-1}$ were prepared and the value of refractive index increment of dextran $(\mathrm{dn} / \mathrm{dc}=0.147)$ was used for molar mass calculation by MALS.

\section{RESULTS AND DISCUSSION}

Synthesis of functional terpenes by thiol-ene coupling. In the present work, we started by studying the synthesis of functional terpenes by thiol-ene chemistry thermally initiated with AIBN initiator. Two types of molecules functionalized by either a carboxylic acid or an amino group were synthesized from the same initial dihydromyrcenol (DHM) 
terpene with two different thiol molecules as depicted in Scheme 2. As reported in literature, ${ }^{27-28}$ the first step of thiol-ene radical reaction is the formation of thiyl radicals $\left(\mathrm{RS}^{\bullet}\right)$ obtained from transfer reaction of the carbon-centered radicals which are generated by the initiator decomposition. The reaction proceeds then via addition of the thiyl radical through the ene functional group to form a carbon radical. For ideal thiol-ene reactions, no homopolymerization is observed and chain transfer of the carbon radical to another thiol functional group follows the addition step, regenerating the thiyl radical and forming the thiol-ene addition product (see Scheme 2). For alkyl thiols and alkenes, the reaction is chaintransfer-limited and first order in thiol functional group concentration. ${ }^{28-29}$

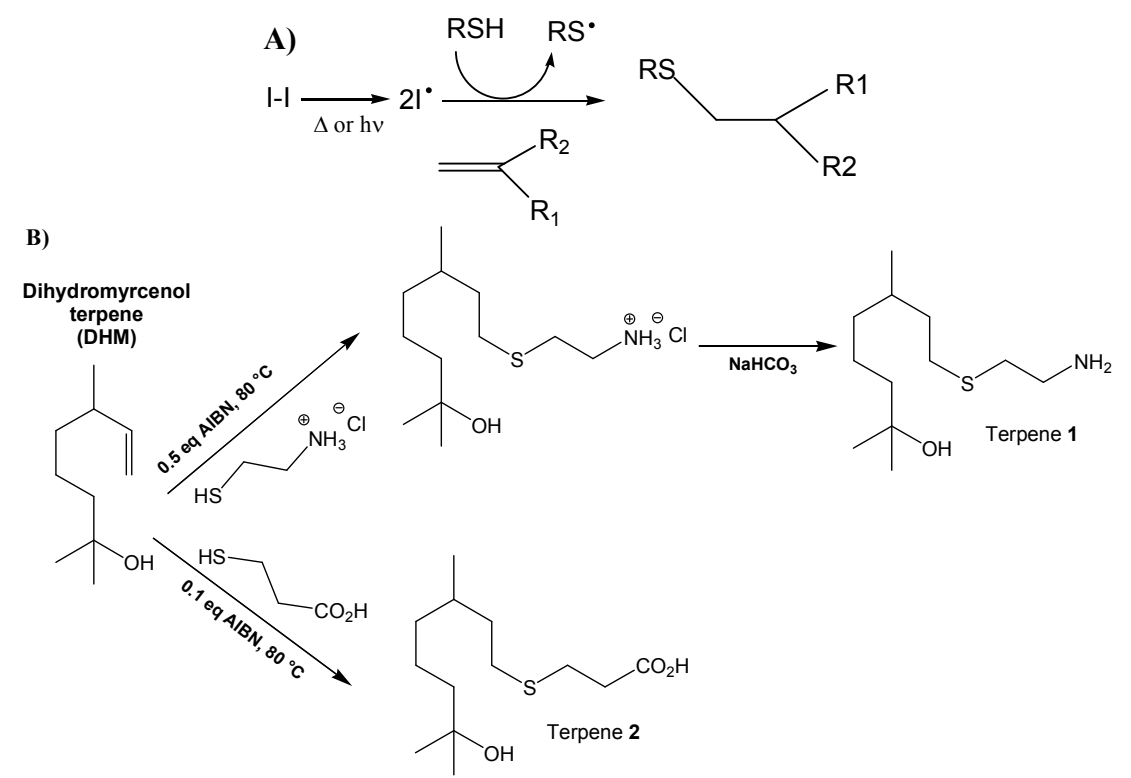

Scheme 2. (A) General principle of radical thiol-ene chemistry using an initiator (I-I) and a thiol transfer agent (RSH); (B) Derivatization of dihydromyrcenol (DHM) terpene by thiolene chemistry to produce functional Terpene $\mathbf{1}$ and Terpene $\mathbf{2}$.

The analysis of the proton NMR spectra of these products (Figure 1) confirmed the success of the thiol-ene reaction performed with either cysteamine hydrochloride or 3-mercaptopropionic acid acting as transfer agent for the coupling reaction (Scheme 2). Indeed, the disappearance 
of the alkene signals of dihydromyrcenol between 4.8 and $5.6 \mathrm{ppm}$ (Figure 1) along with the chemical shift from $2.1 \mathrm{ppm}$ to $1.5 \mathrm{ppm}$ of the $c$ proton in $\alpha$ position of the alkene group (Figure 1 and Figure SI-1), proves the complete addition reaction.

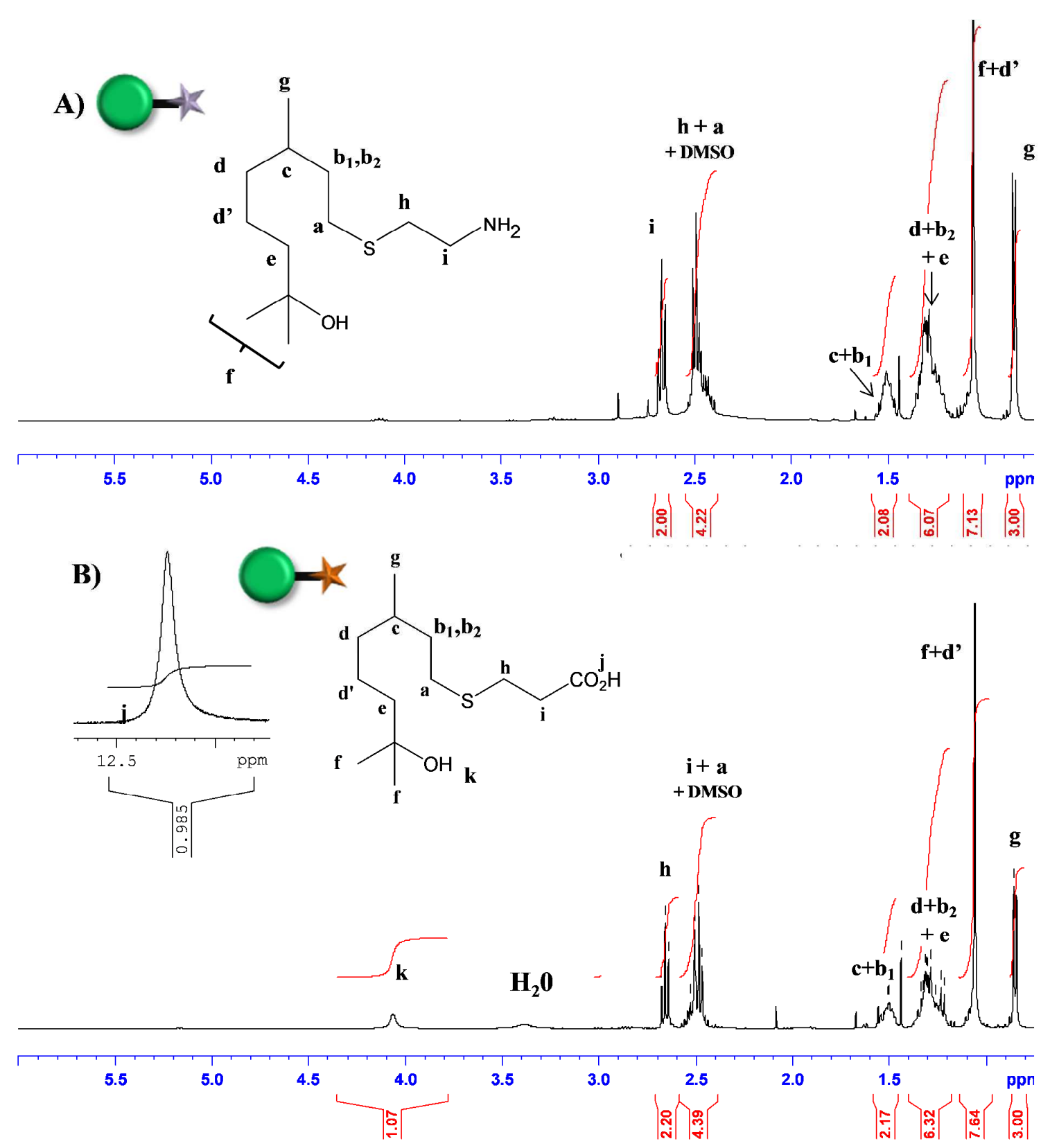

Figure 1. ${ }^{1} \mathrm{H}$ NMR spectra Terpene 1 (A) and Terpene 2 (B) (in DMSO-d6).

For the synthesis of Terpene 1, the matching of the NMR peak integrations of terpenic moiety $\left(I_{i}=2.00(2 \mathrm{H})\right.$ in Figure 1A) with the ones of the thiol moiety $\left(\underline{I}_{g}=3.00(3 \mathrm{H})\right.$ in Figure $\left.1 \mathrm{~A}\right)$ 
confirms the quantitative coupling. While complete disappearance of the alkene signals (Figure 1B) was also observed for the synthesis of Terpene 2 performed in stoichiometric amounts of DHM and 3-mercaptopropionic acid, the NMR integrations of the thiol moiety peak $\left(I_{h}=2.20(2 \mathrm{H})\right)$ exhibits $10 \%$ excess in comparison with the NMR integration of the terpene peak $\left(\underline{I}_{g}=3.00(3 \mathrm{H})\right.$ (see Figure 1B). However, the good agreement between the integration values of the carboxylic acid proton $\left(I_{j}=0.985(1 \mathrm{H})\right)$ and the terpenic protons $\left(I_{g}=\right.$ $3.00(3 \mathrm{H})$ along with the single carboxylic acid peak at $173.3 \mathrm{ppm}$ were observed respectively in the proton (Figure 1B) and the carbon (Figure 2B) NMR spectra of Terpene 2. These observations support the absence of either residual 3-mercaptopropionic acid or oligomers issued from polyesterification between the tertiary alcohol group and the carboxylic acid group.

The analysis of both Terpene 1 and Terpene 2 by two dimensional heteronuclear single bond correlation (HSQC) NMR (Figure 3) enabled us to accurately ascribe the chemical shifts of all protons and carbons. The plots of HSQC NMR analysis confirms the expected structures of both terpenes obtained predominantly by the anti-Markovnikov ${ }^{30}$ addition (Scheme 2). A zoom of HSQC NMR spectrum (see Figure SI-3 in Supporting Information) displays additional methyne $(\delta=39.0 \mathrm{ppm})$ and methyl $(\delta=19.4 \mathrm{ppm})$ groups suggesting the presence of a small amount of the Markovnikov addition product. From the integration of the doublet at $1.10 \mathrm{ppm}$, this secondary structure corresponds to only $5 \mathrm{~mol}-\%$ of the main Terpene 2. Finally, the absence of additional signal of any thioester group between 170 and 210 ppm (see complete ${ }^{13} \mathrm{C}$ NMR spectrum of Terpene 2 in Figure SI-2 of Supporting Information) excludes transesterification side reaction between acid-based terpene and 3mercaptopropionic acid. ${ }^{31}$ 


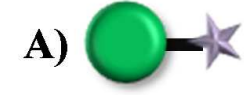




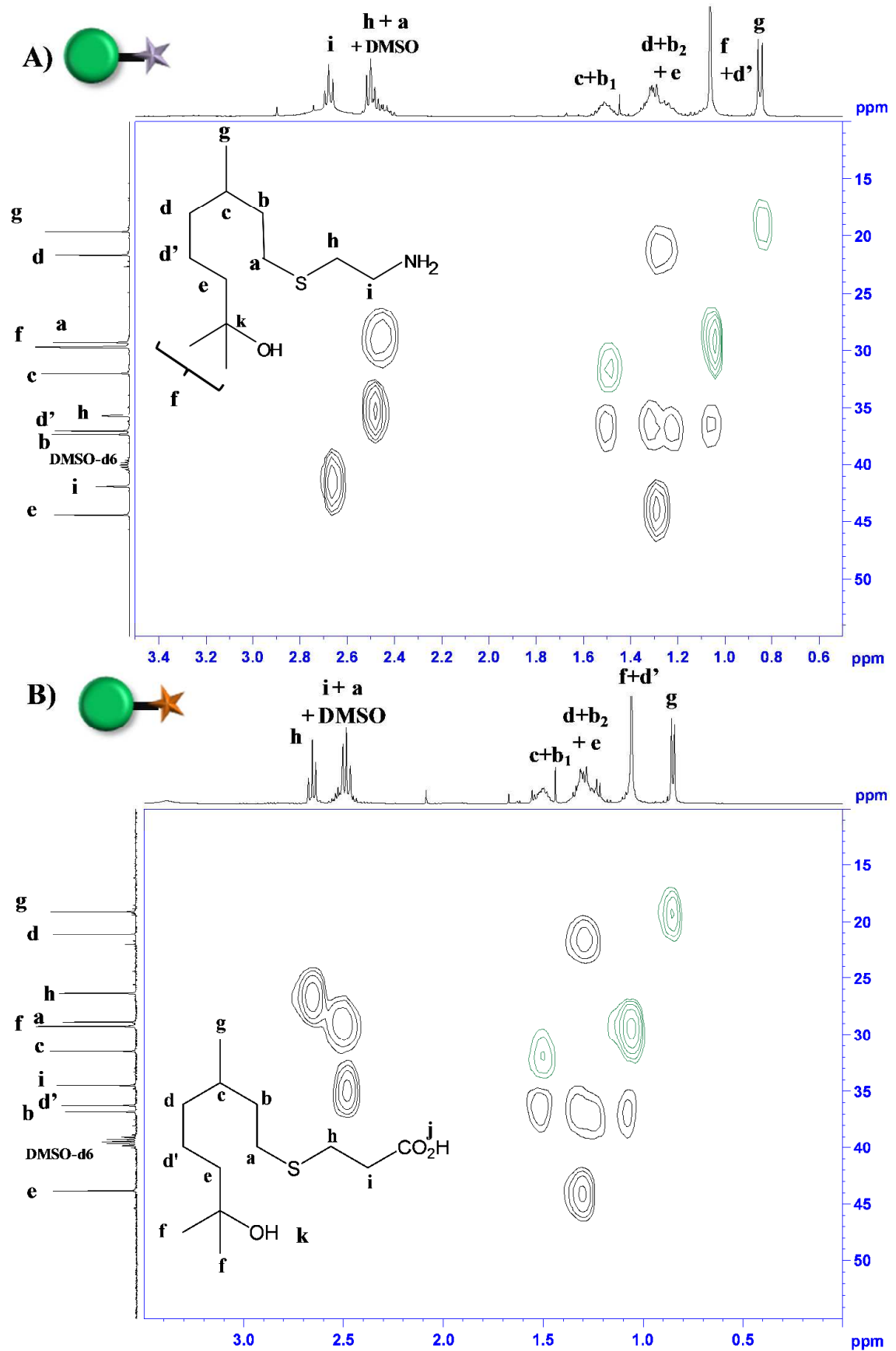

Figure 3. HSQC spectra of Terpene 1 (A) and Terpene 2 (B) in DMSO- $d 6$.

The influence of both thiol and initiator concentrations on the double bond conversion was investigated and the results are reported in Table 1 . We first observed that an excess of thiol transfer agent compared to alkene function is required for a complete coupling reaction. Indeed, a stoichiometric amount of cysteamine hydrochloride versus dihydromyrcenol (entry 1 in Table 1) led to only $50 \%$ of DHM conversion to terpene 2 . While keeping an excess of 
thiol versus ene groups $([\mathrm{RSH}] /[\mathrm{DHM}]>2)$, even lower AIBN concentration conducted to $100 \%$ of coupling efficiency (entries $2-3$ of Table 1 ). We could note that the cysteamine hydrochloride salt was not fully soluble in DHM at the beginning of the reaction but the final product became soluble. On the other hand, 3-mercaptopropionic acid being initially soluble in DHM, the stoichiometry between thiol and ene functional group was sufficient to provide $100 \%$ of double bond conversion (see entries 4-5 in Table 1). Note that adding cysteamine instead of cysteamine hydrochloride resulted in the absence of coupling reaction, neither in bulk nor in DMSO solvent. In most of the previous studies, either Boc-cysteamine ${ }^{32}$ or cysteamine hydrochloride ${ }^{33-36}$ were involved in thiol-ene chemistry. Amine functionalities must be protected or masked by hydrochloric acid because otherwise the thiol is deprotonated and thiyl radical cannot be formed. ${ }^{37}$

Table 1. Thiol-ene chemistry reaction between dihydromyrcenol (DHM) terpene and functional thiols carried out at $\mathrm{T}=80^{\circ} \mathrm{C}$ in bulk. ${ }^{a}$

\begin{tabular}{|c|c|c|c|c|c|c|c|}
\hline Entry & R-SH & $\begin{array}{c}{[\mathrm{DHM}]_{0}} \\
\text { mol. } L^{-1}\end{array}$ & $\begin{array}{c}{[\mathrm{R}-\mathrm{SH}]_{0}} \\
m o l . L^{-1}\end{array}$ & $\begin{array}{c}{[\mathrm{AIBN}]_{0}} \\
m o l . L^{-1}\end{array}$ & $\begin{array}{c}\text { Time } \\
h\end{array}$ & $\begin{array}{c}\text { Conversion }^{a} \\
\%\end{array}$ & Terpene \\
\hline 1 & $\begin{array}{l}\text { Cysteamine } \\
\text { hydrochloride }\end{array}$ & 5.5 & 5.5 & $5.5 \times 10^{-1}$ & 24 & 50 & 1 \\
\hline 2 & $\begin{array}{l}\text { Cysteamine } \\
\text { hydrochloride }\end{array}$ & 5.5 & 16.5 & $5.5 \times 10^{-1}$ & 24 & 100 & 1 \\
\hline 3 & $\begin{array}{l}\text { Cysteamine } \\
\text { hydrochloride }\end{array}$ & 5.5 & 11 & $2.7 \times 10^{-1}$ & 24 & 100 & 1 \\
\hline 4 & $\begin{array}{l}\text { 3-mercaptopropionic } \\
\text { acid }\end{array}$ & 3.6 & 3.6 & $3.6 \times 10^{-1}$ & 4 & 100 & 2 \\
\hline 5 & $\begin{array}{l}\text { 3-mercaptopropionic } \\
\text { acid }\end{array}$ & 3.6 & 3.6 & $3.6 \times 10^{-2}$ & 4 & 100 & 2 \\
\hline
\end{tabular}

Synthesis of $\alpha$-telechelic terpene modified dextran. The average number of anhydroglucose units (AGU) of the initial dextran was equal to 16 according to the number average molar mass determined by aqueous size exclusion chromatography using a MALS detector $\left(M_{\mathrm{n}}=2600 \mathrm{~g} / \mathrm{mol}, M_{\mathrm{w}} / M_{\mathrm{n}}=1.46\right)$. Dextran was functionalized at its reducing end- 
group $D$-glucose residue with the reactive amino group of the Terpene $\mathbf{1}$ in the presence of sodium cyanoborohydride (Scheme 3).



Scheme 3. Synthesis of $\alpha$-telechelic modified dextran (Dext-DHM) synthesized by reductive amination of dextran with terpene 1 .

The proton NMR spectrum of terpene end-modified dextran (Figure 4) which was purified by several precipitations into methanol, shows the characteristic signals of terpene $\mathbf{1}$ protons. The functionalization degree of dextran chains was calculated from the ratio between the area corresponding to the signal of the 3 methylic protons of terpene $\mathbf{1}\left(\delta_{\mathrm{g}}=0.85 \mathrm{ppm}\right)$ and those from the 15 anomeric protons in dextran $\left(\delta_{\mathrm{a}}=4.7 \mathrm{ppm}\right)$. A functionalization degree of $94 \%$ proved the success of the reductive amination reaction. We should note that the absence of dextran degradation during reductive amination has been previously shown by the analysis of the molar mass of dextran before and after the reaction. ${ }^{38}$ The hydrophilic lipophilic balance 
(HLB) of the end-modified dextran polymer (Dext-DHM) was calculated from the simplified Griffin method proposed for non ionic surfactants (HLB $=20 \times$ (molar mass hydrophilic moiety/molar mass hydrophobic moiety)). ${ }^{39}$ The calculated HLB value of the synthesized Dext-DHM (HLB 18.5) is close to Tween 20 non-ionic surfactants (poly(ethylene oxide) sorbitan fatty acid esters with lauric acid hydrophobic group and 20 ethylene oxide units $)^{40}$ which are known for their wide range of emulsifying properties. ${ }^{41-45}$

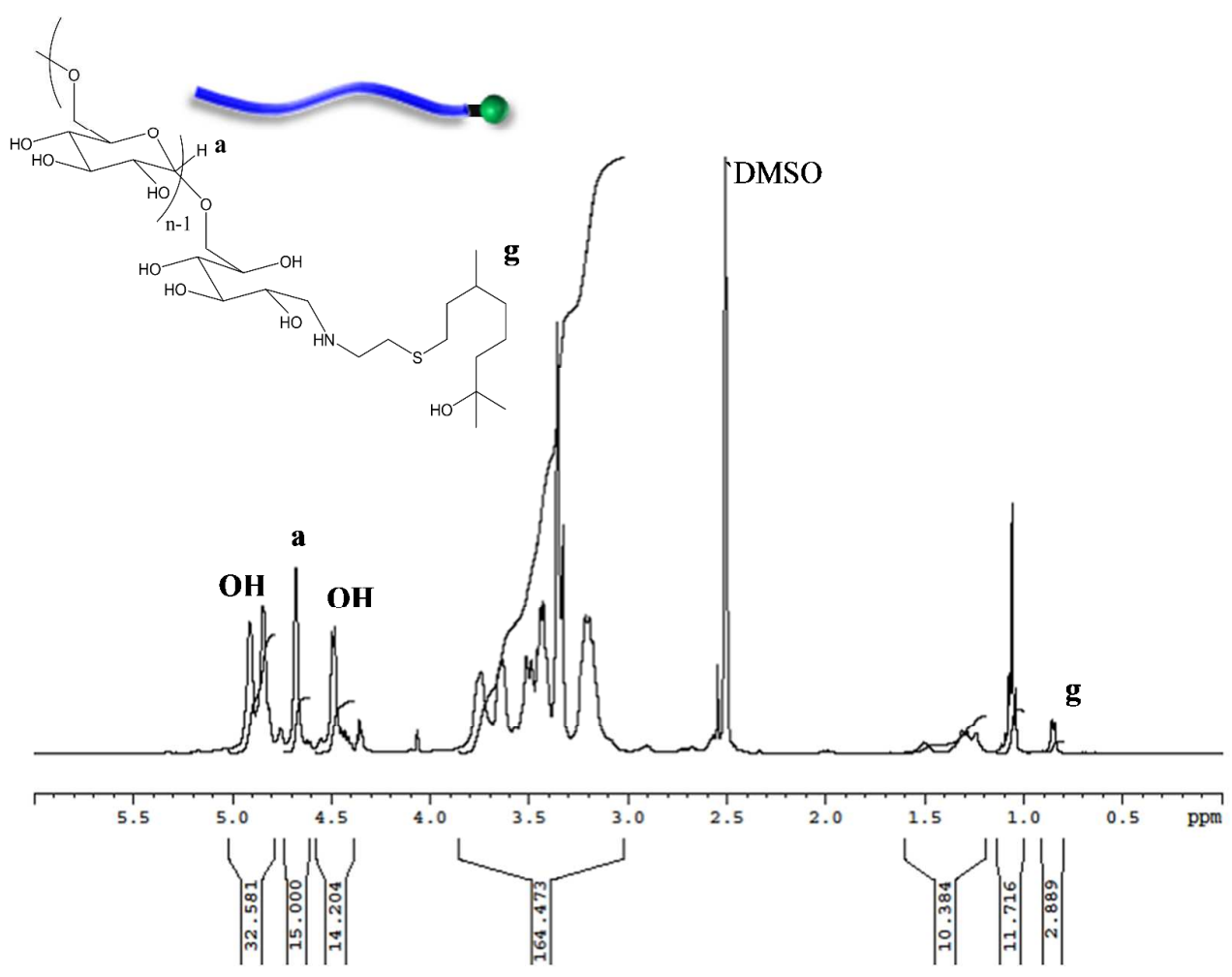

Figure 4. ${ }^{1} \mathrm{H}$ NMR spectrum of Dext-DHM (in DMSO-d6)

Synthesis of terpene grafted dextran: hydrophobically modified dextran. The second strategy focuses on the grafting of the hydrophobic terpene group along the dextran backbone in order to tune the hydrophobic content of the amphiphilic modified dextran via the number of grafted terpene molecules. Terpene $\mathbf{2}$ derivatized with carboxylic acid group was covalently grafted onto the polysaccharide by esterification reaction carried out in dimethylsulfoxide at $60^{\circ} \mathrm{C}$ in the presence of $N, N^{\prime}$-dicyclohexylcarbodiimide (Scheme 4). 

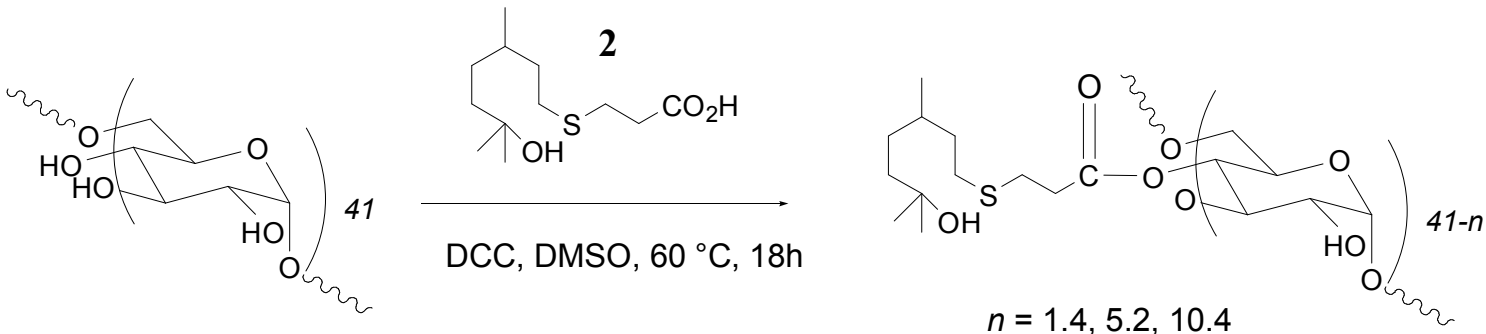

Scheme 4. Synthesis of hydrophobically modified dextran (Dext-graft-DHM) by esterification reaction between dextran and Terpene 2.

The efficient grafting of terpene 2 was evidenced by the presence of characteristic peaks of protons $f$ and $g$ in the NMR spectrum of the amphiphilic copolymer precipitated several times (Figure 5). The number of grafted DHM units per chain of dextran polymer was calculated from equation (1) using the NMR integrations of both DHM methylic protons $\left(I_{\mathrm{g}}\right)$ and dextran anomeric protons $\left(I_{\left(\mathrm{a}^{\prime} \mathrm{a}^{\prime}\right)}\right)$ (see Figure 5). Prior NMR analysis, the hydrophobically modified dextran was carefully precipitated three times into methanol to remove any unreacted terpene 2 .

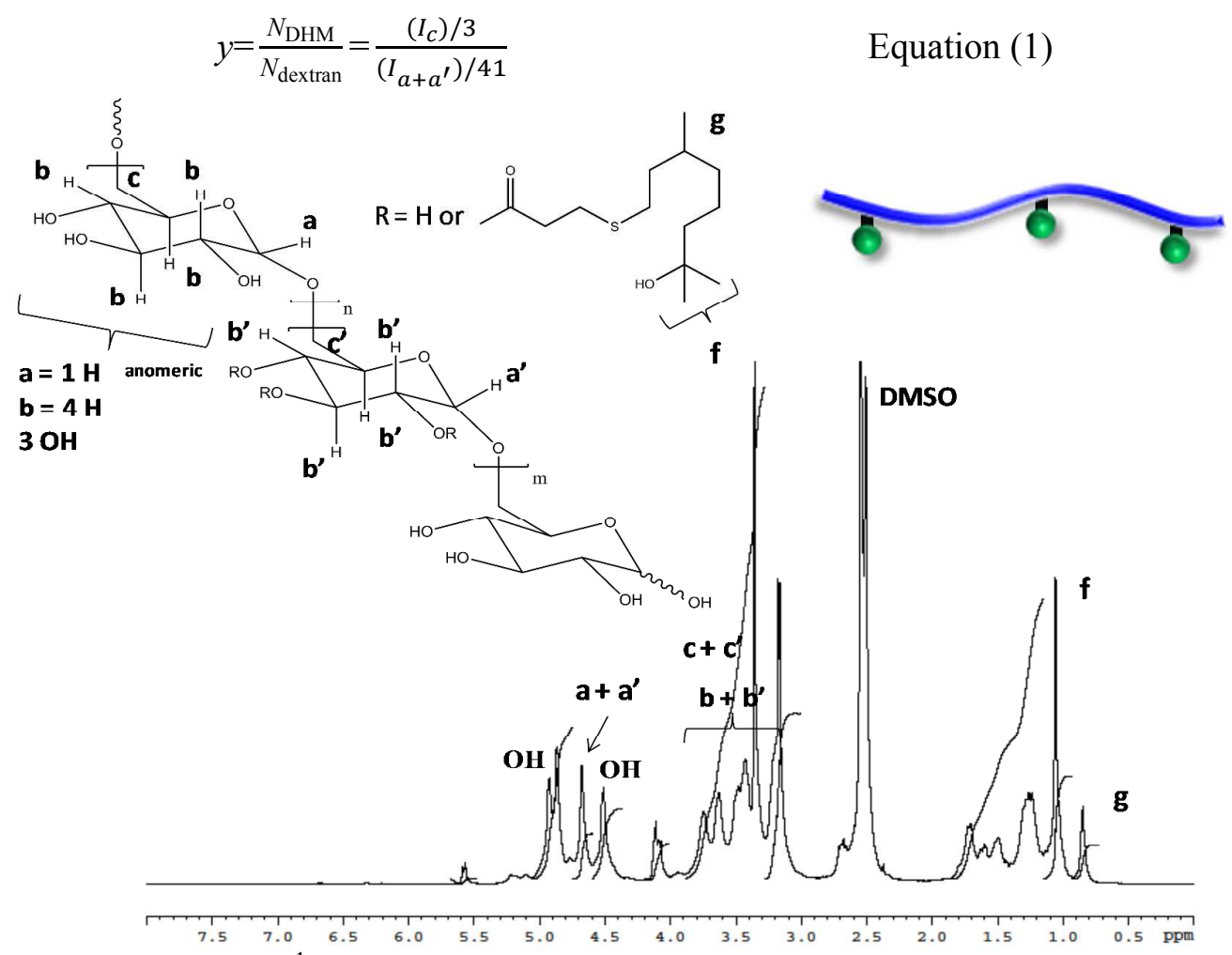

Figure 5. ${ }^{1} \mathrm{H}$ NMR spectrum of Dext-graft-DHM ${ }_{10.4}$ in DMSO- $d 6$. 
As depicted in Table 2, we successfully synthesized three different terpene modified dextrans exhibiting 1,5 and 10 grafted terpene molecules per polysaccharide chain corresponding to a degree of substitution (DS), ie. the number of terpene functions per glucosidic unit, ranging between 2.4 and $24.4 \%$. By applying the simplified Griffin method, ${ }^{39}$ the HLB values of these grafted dextrans ranged between 15 and 19.

Table 2. Synthesis of dextran-graft-DHM by esterification of dextran ${ }^{a}$ with Terpene 2 carried out at $60^{\circ} \mathrm{C}$ for $18 \mathrm{~h}$ in DMSO.

\begin{tabular}{|c|c|c|c|c|}
\hline Exp & Polymer & $x=\frac{n_{\mathrm{DHM}, 0}}{n_{\mathrm{dextran}, 0}} \quad b$ & $y=\frac{N_{\text {DHM }}}{N_{\text {dextran }}} \quad c$ & $\begin{array}{l}\mathrm{DS}^{d} \\
(\%)\end{array}$ \\
\hline 1 & Dext-graft-DHM ${ }_{1.4}$ & 10 & 1.4 & 3.4 \\
\hline 2 & Dext-graft-DHM ${ }_{5.2}$ & 50 & 5.2 & 12.7 \\
\hline 2 & Dext-graft-DHM 10.4 & 100 & 10.4 & 25.4 \\
\hline \multicolumn{5}{|c|}{$\begin{array}{l}{ }^{a} \text { Dextran } 8 \text { polymer from Serva Electrophoresis }{ }^{\circledR}: M_{\mathrm{n}, \mathrm{dext}}=6600 \mathrm{~g} \cdot \mathrm{mol}^{-1}, M_{\mathrm{w}} / M_{\mathrm{n}}=2.2, N_{\mathrm{AGU}} \\
=41\end{array}$} \\
\hline \multicolumn{5}{|c|}{$\begin{array}{l}{ }^{b} \text { Initial number of moles of DHM ter } \\
=\left(m_{\mathrm{DHM}, 0} / F W_{\mathrm{DHM}}\right) /\left(m_{\mathrm{dextran}, 0} / M_{\mathrm{n}, \mathrm{dext}}\right)\end{array}$} \\
\hline \multicolumn{5}{|c|}{$\begin{array}{l}{ }^{c} \text { Average final number of DHM units per dextran polymer chain analyzed by proton NMR of } \\
\text { the precipitated of Dext-graft-DHM (see Figure } 5 \text { and equation (1)). }\end{array}$} \\
\hline
\end{tabular}

Stabilization of DHM Terpene Liquid miniemulsion. It was considered of interest for cosmetic formulations to study the surface active properties of the terpene graft dextrans for emulsifying hydrophobic terpene droplets in water. The aim was to produce stable miniemulsion of dihydromyrcenol (DHM) in water stabilized by the amphiphilic biopolymers in order to facilitate the transfer of hydrophobic terpene molecules used as fragrance into aqueous formulations. For that purpose, the dihydromyrcenol was mixed with hexadecane, a 
well-known efficient hydrophobe co-surfactant which ensures stability of the liquid miniemulsion by suppressing the interdroplet mass diffusion, named Ostwald Ripening. ${ }^{21,46-47}$ The hydrophobic phase composed of DHM and hexadecane was mixed with a water phase containing the terpene modified dextran prior decreasing the oil droplet size by applying shear via ultrasonication (see experimental part). The stability of the liquid DHM miniemulsion (10 $\mathrm{wt} \% \mathrm{DHM}$ in water) was followed with time and the images of the emulsion are displayed in Table 3. As expected, it was not possible to form any stable emulsion with the native hydrophilic dextran.

While Dext-graft-DHM ${ }_{1.4}$ polymer containing only one terpene molecule per dextran (degree of substitution $=2.4 \%$ ) showed poor stabilizing efficiency with evident creaming observed after 24 hours, Dext-graft-DHM 5.2 and Dext-graft-DHM 10.4 polymers gave rise to stable miniemulsions. The droplet sizes were measured by dynamic light scattering showing average hydrodynamic diameter of the main population centered at $320-340 \mathrm{~nm}$. A second population of larger droplet was observed with a non-negligible intensity as light scattering is more intense for larger colloids. Nevertheless, the liquid miniemulsion stabilized by Dextgraft-DHM ${ }_{5.2}$ was composed of $98 \%$ by number of the smallest $320 \mathrm{~nm}$ droplets. In conclusion, the renewable terpene modified dextrans are able to act as efficient stabilizer of direct terpene miniemulsion. The most efficient stabilizer is the dextran grafted with the intermediate number of terpene molecules, ie Dext-graft-DHM ${ }_{5.2}(\mathrm{DS}=12 \%)$, which is slightly more efficient stabilizer than Dext-graft-DHM ${ }_{10.4}(\mathrm{DS}=24 \%)$. This trend is consistent with previous results reported by Durand et al..$^{22}$ who showed a decrease of interfacial tension between dodecane and water by increasing the degree of substitution of hydrophobically modified dextrans from DS $=6 \%$ to DS $=31 \%$. It was suggested that the interfacial tension lowering resulted from the preferential intramolecular aggregation with 
(Terpene 2). Novel amphiphilic biomass-based polymers were successfully synthesized by coupling the functional terpenes with dextran polysaccharide, either by reductive amination or by esterification reactions. The chosen synthetic pathways offer the possibility to synthesize either terpene end-modified dextran or terpene-grafted dextrans. When using the grafted amphiphilic polymers as surface active macromolecular species, stable miniemulsion of dihydromyrcenol terpene in water can be obtained with average droplet hydrodynamic diameter of 320-340 nm. The most efficient emulsifier was the dextran hydrophobically modified with five terpene molecules per chain, ie a degree of substitution of $12 \%$. Studies of the stabilization efficiency for polymeric colloids are currently being in progress by comparing the stabilization properties of the terpene grafted dextran with terpene grafted poly(acrylic acid).

\section{ASSOCIATED CONTENT}

\section{Supporting Information}

${ }^{1} \mathrm{H}$ and ${ }^{13} \mathrm{C}$ NMR spectra of initial DHM terpene, ${ }^{1} \mathrm{H}$ NMR of Terpene 2 and COSY 2D-NMR spectra of both synthesized functional terpenes are provided. This material is available free of charge via the Internet at http://pubs.acs.org.

\section{AUTHOR INFORMATION}

\section{Corresponding Author}

*E-mail: maud.save@univ-pau.fr

\section{Author Contributions}

All authors have given approval to the final version of the manuscript.

\section{ACKNOWLEDGEMENTS}

The authors are grateful to Région Aquitaine, LVMH and DRT for financial support. The authors thank Dr. Julien Bernard, Agnès Crepet from IMP@INSA Lyon for aqueous SEC 
analysis of dextran and Abdel Khoukh (IPREM-EPCP) for NMR analyses. ANR-10-EQPX-

16 XYLOFOREST funding is acknowledged.

\section{REFERENCES}

(1) Stevens, C. V.; Meriggi, A.; Booten, K. Biomacromolecules 2001, 2, 1-16.

(2) Lahaye, M.; Robic, A. Biomacromolecules 2007, 8, 1765-1774.

(3) Rose, M.; Palkovits, R. Macromol. Rapid Commun. 2011, 32, 1299-1311.

(4) Figueiredo, J. A.; Ismael, M. I.; Anjo, C. M. S.; Duarte, A. P., Cellulose and Derivatives from Wood and Fibers as Renewable Sources of Raw-Materials. In Carbohydrates in Sustainable Development I: Renewable Resources for Chemistry and Biotechnology, Rauter, A. P.; Vogel, P.; Queneau, Y., Eds. Springer-Verlag Berlin: Berlin, 2010; Vol. 294, pp 117-128.

(5) Wilbon, P. A.; Chu, F. X.; Tang, C. B. Macromol. Rapid Commun. 2013, 34, 8-37.

(6) Yao, K. J.; Tang, C. B. Macromolecules 2013, 46, 1689-1712.

(7) Zhao, J. P.; Schlaad, H., Synthesis of Terpene-Based Polymers. In Bio-Synthetic Polymer Conjugates, Schlaad, H., Ed. Springer-Verlag Berlin: Berlin, 2013; Vol. 253, pp 151-190.

(8) Sharma, S.; Srivastava, A. K. J. Macromol. Sci., Part A: Pure Appl.Chem. 2003, A40, 593-603.

(9) Sharma, S.; Srivastava, A. K. Polym.-Plast. Technol. Eng. 2003, 42, 485-502.

(10) Sharma, S.; Srivastava, A. K. Eur. Polym. J. 2004, 40, 2235-2240.

(11) Sharma, S.; Srivastava, A. K. J. Appl. Polym. Sci. 2004, 91, 2343-2347.

(12) Firdaus, M.; de Espinosa, L. M.; Meier, M. A. R. Macromolecules 2011, 44, 72537262.

(13) Zhao, J. P.; Jeromenok, J.; Weber, J.; Schlaad, H. Macromol. Biosci. 2012, 12, $1272-$ 1278.

(14) Zhao, J. P.; Schlaad, H.; Weidner, S.; Antonietti, M. Polym. Chem. 2012, 3, 1763 1768 .

(15) Singh, V.; Kumar, P.; Sanghi, R. Prog. Polym. Sci. 2012, 37, 340-364.

(16) Tizzotti, M.; Charlot, A.; Fleury, E.; Stenzel, M.; Bernard, J. Macromol. Rapid Commun. 2010, 31, 1751-1772.

(17) Ydens, I.; Rutot, D.; Degee, P.; Six, J. L.; Dellacherie, E.; Dubois, P. Macromolecules 2000, 33, 6713-6721.

(18) Wang, C. Q.; Li, G. T.; Tao, S. Y.; Guo, R. R.; Yan, Z. Carbohydr. Polym. 2006, 64, 466-472.

(19) Habibi, Y.; Goffin, A. L.; Schiltz, N.; Duquesne, E.; Dubois, P.; Dufresne, A. J. Mater. Chem. 2008, 18, 5002-5010.

(20) Qiu, X. Y.; Wang, C. Q.; Shen, J. A.; Jiang, M. W. Carbohydr. Polym. 2011, 83, $1723-1729$.

(21) Durand, A.; Marie, E.; Rotureau, E.; Leonard, M.; Dellacherie, E. Langmuir 2004, 20, 6956-6963.

(22) Durand, A.; Dellacherie, E. Colloid Polym. Sci. 2006, 284, 536-545.

(23) Durand, A. Colloid Polym. Sci. 2008, 286, 1505-1510.

(24) Obiols-Rabasa, M.; Ramos, J.; Forcada, J.; Esquena, J.; Solans, C.; Levecke, B.; Booten, K.; Tadros, T. F. Langmuir 2010, 26, 7717-7724.

(25) Kaewprapan, K.; Baros, F.; Marie, E.; Inprakhon, P.; Durand, A. Carbohydr. Polym. 2012, 88, 313-320.

(26) Claudino, M.; Jonsson, M.; Johansson, M. RSC Adv. 2013, 3, 11021-11034. 
(27) Hoyle, C. E.; Bowman, C. N. Angew. Chem., Int. Ed. 2010, 49, 1540-1573.

(28) Hoyle, C. E.; Lee, T. Y.; Roper, T. J. Polym. Sci., Part A-1: Polym. Chem. 2004, 42, 5301-5338.

(29) Cramer, N. B.; Reddy, S. K.; O'Brien, A. K.; Bowman, C. N. Macromolecules 2003, 36, 7964-7969.

(30) Posner, T. Ber. Dtsch. Chem. Ges. 1905, 38, 646-657.

(31) Jaillet, F.; Desroches, M.; Auvergne, R.; Boutevin, B.; Caillol, S. Eur. J. Lipid Sci. Technol. 2013, 115, 698-708.

(32) Silverstein, J. S.; Casey, B. J.; Natoli, M. E.; Dair, B. J.; Kofinas, P. Macromolecules 2012, 45, 3161-3167.

(33) Franz, N.; Menin, L.; Klok, H. A. Org. Biomol. Chem. 2009, 7, 5207-5218.

(34) Jia, Z. F.; Liu, J. Q.; Davis, T. P.; Bulmus, V. Polymer 2009, 50, 5928-5932.

(35) Stemmelen, M.; Pessel, F.; Lapinte, V.; Caillol, S.; Habas, J. P.; Robin, J. J. J. Polym. Sci., Part A-1: Polym. Chem. 2011, 49, 2434-2444.

(36) Auvergne, R.; Desroches, M.; Clerc, S.; Carlotti, S.; Caillol, S.; Boutevin, B. React. Funct. Polym. 2012, 72, 393-401.

(37) Krannig, K. S.; Schlaad, H. J. Am. Chem. Soc. 2012, 134, 18542-18545.

(38) Jeong, Y. I.; Kim, D. G.; Kang, D. H. Journal of Chemistry 2013, DOI $10.1155 / 2013 / 414185$.

(39) Griffin, W. C. Cosmet. Chem. J. Soc. 1949, 1, 311-326.

(40) Pasquali, R. C.; Taurozzi, M. P.; Bregni, C. Int. J. Pharm. (Amsterdam, Neth.) 2008, 356, 44-51.

(41) Eskandani, M.; Hamishehkar, H.; Dolatabadi, J. E. N. DNA and Cell Biology 2013, 32, 498-503.

(42) Xin, X.; Zhang, H. X.; Xu, G. Y.; Tan, Y. B.; Zhang, J.; Lv, X. Colloids Surf., A 2013, $418,60-67$.

(43) Losada-Barreiro, S.; Sanchez-Paz, V.; Bravo-Diaz, C. J. Colloid Interface Sci. 2013, 389, 1-9.

(44) Qian, C.; Decker, E. A.; Xiao, H.; McClements, D. J. J. Am. Oil Chem. Soc. 2012, 89, 17-28.

(45) Gulseren, I.; Coupland, J. N. J. Am. Oil Chem. Soc. 2007, 84, 621-629.

(46) Mishchuk, N. A.; Verbich, S. V.; Dukhin, S. S.; Holt, O.; Sjoblom, J. J. Dispersion Sci. Technol. 1997, 18, 517-537.

(47) Landfester, K. Macromol. Rapid Commun. 2001, 22, 896-936.

Table of Contents Graphic (TOC)

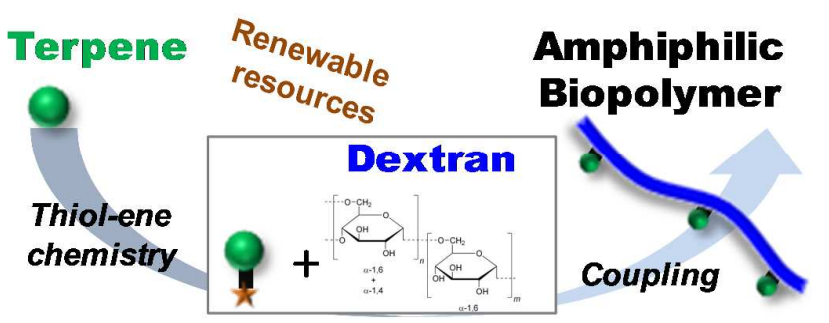

